\title{
The Augustan Angle: Civilised Contingency and Normative Discourse
}

The readings of the last chapter have taken us to the threshold of the eighteenth century. By 1700, the neoclassical discourse of contingency and probability had been established as a coherent and dominant cultural programme as part of the general process of political and social consolidation in Britain. Towards the end of the century, the 'Glorious Revolution' implemented a constitutional form of monarchy and a liberal cultural ideology (Whiggism), including - for Protestants, at least - religious toleration. This created the preconditions for a crucial shift of balance between metaphysics, politics, and epistemology. The problems of reconciling their competing claims could now be solved - or at least 'rationalised away' - by funnelling the problematic experiential dimensions of reason, nature, and faith into the philosophical and moral terms of 'common sense' and 'politeness'. The epistemological and political thinking of John Locke is exemplary in this respect. Locke's empirical and practical rationalism allows for those dimensions of reality that, for Browne and others earlier in the century, had formed such a difficult, knotted complex - religion, politics, and secular (individual and social) frames of reference - to be disentangled. In contrast to Browne, Locke holds that the human faculties of perception are exactly matched to earthly requirements and that it is therefore meaningless to yearn for knowledge that transcends these faculties. In the Essay Concerning Human Understanding (1690), Locke remarks that " $[t]$ he infinite wise Contriver of us, and all things about us, hath fitted our Senses, Faculties, and Organs, to the conveniences of Life, and the Business we have to do here" $(2.23 .12 ; 1979,302)$. The tensions that had previously led to wars of religion are now relaxed by this deistic interpretation of the cosmos and its related view of natural rights, and these Lockean ideas have an impact on many other areas of human life.

As portrayed in Congreve's The Way of the World, the elite has become secular and self-supporting, self-reproducing, living according to its own laws. Secular problems are addressed by secular solutions. Although marriages still have to take place in a church, they are no longer made in heaven but on earth, based on mutual interests and agreements (the 'proviso') - not excluding, obviously, love, as passion and reason (Luhmann 1987). The books of the Puritans have their backs turned to this society, becoming objects of decoration on the mantelpiece in ironic reminiscence of the dii familiares. The competing claims of reason, nature, and faith are defused in the concepts of common sense and gentlemanly politeness. These terms and their implied rules now regulate civil conversation, including knowing where and when to stop or what not to talk about.

As literature (in the sense of belles lettres) becomes a part of social conversation, it is increasingly bound by the rules of what is deemed acceptable, and its decorum now implies a social and moral correspondence between authors, genres, and readers. 
This correlation undergoes a long development throughout the eighteenth century, from Pope, Johnson, and Swift to Sterne and Fielding, and it is still clearly present in the early nineteenth century. One can see this quite well, for instance, in Jane Austen's Persuasion (1818). Here, conversation is the judge of a person's character: "He sat down with them, and improved their conversation very much. There could be no doubt of his being a sensible man. Ten minutes were enough to certify that. His tone, his expressions, his choice of subject, his knowing where to stop, - it was all the operation of a sensible, discerning mind" $(2006,155)$. But the point extends to literature itself, and the interaction between reading and the mind. Reading the wrong kind of literature - in this case, Byron's “impassioned descriptions of hopeless agony” (108) in works like The Giaour - may lead to interventions like the one that Anne Elliot attempts with the mournful Captain Benwick: "[. . .] she ventured to hope he did not always read only poetry; and to say, that she thought it was the misfortune of poetry, to be seldom safely enjoyed by those who enjoyed it completely; and that the strong feelings which alone could estimate it truly, were the very feelings which ought to taste it but sparingly" (108). Faced with the possibly damaging effects of excessive passion in poetry, Austen's protagonist recommends "a large allowance of prose in his daily study; and on being requested to particularize, mentioned such works of our best moralists, such collections of the finest letters, such memoirs of characters of worth and suffering, as occurred to her at the moment as calculated to rouse and fortify the mind by the highest precepts, and the strongest examples of moral and religious endurances" (108-109). Obviously, Austen's point here goes beyond a merely generic or moral contrast between different kinds of literature; as Anne realises after lecturing the Captain, "she had been eloquent on a point in which her own conduct would ill bear examination" (109).

After 1688, literature becomes less overtly political and increasingly more selfconsciously aesthetic or aestheticised as it is taken out of political and pragmatic concerns and embedded in a new contexture of polite conversation. Milton, to name only one example, is "increasingly depoliticized" after the Restoration, "and eventually memorialized at the very centre of the political and cultural establishment, by a bust mounted in Westminster Abbey in 1737” (Zwierlein 2019, 650; see also Zwierlein 2001, Zwicker 2003, 306-307). John Dennis, Charles Gildon, later Addison and Steele further an aesthetic and polite approach to literary writing (Dennis 1939-40, Gildon 1710, Addison 1970; cf. Reiss 1992, 89, 162). There are at least two sides to this process. One is the increasing idealisation of literature as having a 'higher' value, in the way that a work of art not limited by its historical context receives a quasi-timeless stamp of validity. This will lead on to the nineteenth- and twentieth-century (Arnoldian and Eliotian) harnessing of literature for the purposes of education, as a record of "the best which has been thought and said in the world" (Arnold 1971, 6). The other side is the debasement of literature, particularly poetry, as a useless or even dangerous pursuit, which today has made the job of justifying the value of literature (even in education) more and more difficult. This view has an early supporter in John Locke: in Some Thoughts 
Concerning Education, he advises parents to suppress any poetic inclinations in their children as a waste of time, which could be used for gainful employment (Locke 1989, 230-31).

As we have seen, in The Way of the World it is no longer the meaning of a text that counts but its form and its practical use. With regard to poetry, this use is primarily conversational. It is literature, as Kenneth Burke famously called it, "as equipment for living” (1957). When Mirabell and Millamant recite poetry to each other, they open up an escape hatch from convention. Literature in this use offers a view of alternative possibilities of living. It allows readers to compare between different modes of seeing and making the world, also in regard to the limits of various frames of reference or social systems (money, love, class, gender, etc.). It allows them to see behind and beyond prevailing norms. Arguably, this is an important aspect of 'culture', understood in an active sense as the cultivation of comparative observations while acknowledging the limitations of one's point of view (Luhmann 1995). This kind of literature - realised, above all, in the form of the novel from the eighteenth century onwards - no longer strives to represent an underlying unity as the foundation for any and all aspects of reality (as Davenant's idea of the epic poem still did and his Gondibert spectacularly failed to achieve). On the contrary, it recodifies "social and cultural norms", "detach[-ing] prevailing norms from their functional context" and "focusing on their deficiencies" (Iser 2006, 63) in order to show the possibilities and limitations of these norms as they carve up reality into manageable chunks.

However, although this is arguably what works of literature do, it is rarely if ever made explicit by authors and critics in the early modern period. In theory, literary communication is relegated to the sphere of polite conversation. In an increasingly commercial society, poetry begins to lose its former cachet of aristocratic patronage; writers like Defoe resort to all sorts of businesses just to be fed. Stylistically, the copious, humanist and Euphuist manner of writing is replaced by one defined by clarity and precision. The new linguistic ideal is "mathematical plainness", as Thomas Sprat explains in 1667 when he drafts his guidelines for the Royal Society $(1958,113)$ :

to reject all the amplifications, digressions, and swellings of style: to return back to the primitive purity, and shortness, where men deliver'd so many things, almost in an equal number of words. They have exacted from all their members a close, naked, natural way of speaking; positive expressions, clear senses; a native easiness, bringing all things as near the mathematical plainness as they can; and preferring the language of Artizans, countrymen, and Merchants, before that of Wits and Scholars.

As we have seen, the heterogeneity of writing styles in the seventeenth century can be attributed to competing concepts of language and discourse. These concepts carry social, political, and religious implications that could not be brought to any kind of consensus before the socio-political settlement after the 1688 revolution because, from Bacon to Locke, linguistic thought and stylistic habits were inextricably connected with mutually opposing ideas of society, religion, and politics. Linguistic reform in the 
context of the Royal Society, for instance, was pursued for a Hobbesian cause: its goal was to achieve the peaceful exchange of knowledge for the benefit of the commonwealth and thereby to avoid "a warlike State of Nature, one against the other" (Sprat 1958, 33; cf. Salmon 1979, Aarselff 1982, Hüllen 1989). Different ideas on the nexus between language and society also have an impact on aesthetic or formal decisions. For example, rhymed heroic couplets were mostly regarded as a royalist and courtly form of discourse appropriate to the high style, as opposed to blank verse or prose. For Dryden, rhyme was "more fit for the ends of government" (Dryden 1967, 7) whereas blank verse for Milton is "an example [. . .] of ancient liberty recover'd [. . .] from the troublesome and modern bondage of rhyming" (Milton 1998, 55). Entire genres stand and fall with their political embedding: the demise of heroic drama, with its elaborately stylised and elevated speeches, occurs in parallel to the crisis of the Stuart monarchy in the 1670s and its loss of power in 1688 (Kamm 1996, 167, 452-53; Berensmeyer 2011, 134).

The cultural locus and socio-spatial model of the neoclassical discursive ideal is no longer the humanist library or the cabinet of wonder but the public coffee-house, which cultivates exactly this "close, naked, natural way of speaking” and "native easiness" among people of different ranks and professions that Sprat seeks to encourage. ${ }^{111}$ Furthermore, the new cultural configuration is characterised by a clear hierarchical distinction between cognitive and experiential, mental and physical modes. The ideal of a 'pure' and 'natural' style does not betoken any simple, unproblematic referentiality of language, but is in fact a complex strategic venture, from within a strict hierarchy of communicative levels, of avoiding rhetorical extremes (see Kroll 1992, 21). In this hierarchical distinction, reason in 'plain style' becomes the medium of truth, whereas passion (and, by extension, flowery, figurative, or poetic language) is found to be the medium of deceit. In a chapter on "the Abuse of Words" in the Essay concerning Human Understanding, Locke - following Hobbes - undertakes a neat separation of discursive styles, distinguishing between "Discourses, where we seek rather Pleasure and Delight" from those that provide "Information and Improvement". Only in the former type are the "Ornaments" of rhetoric legitimate means of communication; in the latter, rhetoric is nothing but a "powerful instrument of Error and Deceit”:

111 Much, perhaps too much, has been made of the impact of coffee-houses on the development of democratic structures and ideas. But their genuine appeal as models of intelligent conversation (and, by extension, an ideal type of literary communication) in The Spectator and elsewhere is beyond question. See, for example, Boswell's exercises of recording 'typical' coffee-house dialogues in his London diary - already based on the model of The Spectator (Boswell 1950, 74-76, entry for 11 Dec. 1762), and see also a number of observations on coffee (-house) culture in Schivelbusch 1992 and Kroll 2000. Pincus 1995 gives evidence of coffee-houses in the early 1650s, and finds little to support Habermas's claim that the socio-political impact of coffee-houses only began after 1688 . Contrary to a number of views on the matter, Pincus asserts the crucial role of coffee-houses for developing a political public sphere in the Restoration period; he also dispenses with the claim that they excluded women. 
But yet, if we would speak of Things as they are, we must allow, that all the Art of Rhetorick, besides Order and Clearness, all the artificial and figurative application of Words Eloquence hath invented, are for nothing else but to insinuate wrong Ideas, move the Passions, and thereby mislead the Judgment; and so indeed are perfect cheat[.] $\quad$ (Locke 1979, 508; 3.10.34)

Dryden is particularly explicit on this in his Religio Laici, a text that is cast in the mould of 'religio' writing established by Browne and published in the year of Browne's death, 1682. At the end of his preface, Dryden develops a poetics of instructive literary writing along a clear dividing line between plain style/reason/truth and figurative language/passion/deceit:

The Expressions of a Poem, design'd purely for Instruction, ought to be Plain and Natural, and
yet Majestick: for here the Poet is presum'd to be a kind of Law-giver, and those three qualities
which I have nam'd are proper to the Legislative style. The Florid, Elevated, and Figurative
way is for the Passions; for Love and Hatred, Fear and Anger, are begotten in the Soul by
shewing their Objects out of their true proportion; either greater than the Life, or less; but
Instruction is to be given by shewing them what they naturally are. A Man is to be cheated
into Passion, but to be reason'd into Truth.
(Dryden 1972, 109)

Whereas, in Browne, these epistemic levels are layered and context-dependent, in Locke and Dryden they are stratified and systematised according to what Dryden calls "their true proportion" $(1972,109)$ and what Locke refers to as "Propriety of Speech" $(1979,514 ; 3.11 .11)$. These comments need to be read in the context of seventeenth-century debates on linguistic refom in relation to political moderation and common sense, as well as the problem of 'enthusiasm'. As Shaftesbury writes in his essay Sensus communis (1709): "The only poison to reason is passion" (1999, 43; cf. Heyd 1995). Language, for Locke, is predominantly a social and intersubjective medium of exchange: "Speech being the great Bond that holds Society together, and the common Conduit, whereby the Improvements of Knowledge are conveyed from one Man, and one Generation to another" (1979, 509; 3.11.1). Browne's cherished adiaphora or "points indifferent" can then be disparaged and set aside as "points obscure" that do not serve "the Improvements of Knowledge". For Locke and others, questions of style can be - and indeed have to be - decided according to decorum, propriety, and probability, in accordance with the appropriate rules of genre. In such a decision process, undecidable questions are excluded for the sake of public peace:

'Tis some Relief, that points not clearly known, Without much hazard may be let alone:

And, after hearing what our Church can say,

If still our Reason runs another way,

That private Reason 'tis more Just to curb,

Than by Disputes the publick Peace disturb.

For points obscure are of small use to learn:

But Common quiet is Mankind's concern.

(Dryden 1972, 122, 11. 443-50) 
In Dryden's Religio Laici (1682), the conflict is no longer one of private peace being disturbed by public war, but one of "publick Peace" potentially disturbed by "private Reason". This rationalist attitude towards religion does not first arise as a Whig concept in the context of the 'Glorious Revolution' but develops gradually in response to the excesses of religious fundamentalism and Puritanism during Civil War and 'Interregnum'. Naturally, Dryden's argument for religious quietism, appearing in the midst of the Exclusion Crisis, is - as usual - not without its own polemical and partisan edge in favour of Stuart crypto-Catholicism (Zwicker 1998a, 194-95). It was a predominant concern of Restoration England to curb extremes for the sake of maintaining public order and political stability.

Compared to this, Sir Thomas Browne indeed appears "like Janus in the field of knowledge" (Browne 2012, 78, Religio 2.8). He develops an idea of the contextdependent validity of more than one approach to knowing reality but he does not yet think of translating his epistemological programme into a politically viable strategy of social action. For Dryden, Locke, and later the third Earl of Shaftesbury, such a strategy is the goal as they plead for 'common sense' to enlist in the service of 'common quiet'. The 'age of reason' develops a normative account of human psychology and social behaviour: the ideals of civility and sociability and the necessity of 'public peace' for public welfare override 'private reason' in order to manage and accommodate political and religious differences. This new dispensation of 'civic humanism' (Pocock 1975) establishes a new way of dealing with contingency and probability. Politically instituted in the Williamite settlement and its Whig interpretation after 1688, this discourse is codified and popularised in the writings of Locke, Defoe, and Shaftesbury. The discourse of probability and contingency is gradually developed in the post-Interregnum era, performatively embodied in the theatrical practices of Restoration drama and neoclassical poetry, tested in political and economic theory as well as practice, and ultimately established as the widely accepted norm of the age. In this way, 'neoclassicism' (understood as a discourse that connects social, political, and aesthetic developments) becomes a normative and powerful cultural force throughout the eighteenth century (Paulson 1996, xvi), until its homologies are seen as constraining and ready for a radical transformation in the Romantic period.

All this entails significant consequences for the discursive handling of differences between 'individualities' and 'textualities'. In the political sphere, neoclassical discourse promotes non-violence and the use of "degrees of assent" (Locke 1979, 4.16). With regard to language, it establishes an anti-deterministic attitude, for which signs and referents are connected in an arbitrary manner, so that meaning cannot be secured a priori but has to be established within discourse itself. Neoclassical poetics comes to "respect the reader's individual integrity" (Kroll 1991, 77) because literary communication can only work under these conditions if the recipient is willing to cooperate. Communication becomes less hierarchical: the reader is no longer seen as a “prisoner” (Davenant 1971, 17) but as a partner, whose contingent individuality is accepted as the norm. Moreover, if no interpretation of a text can be forced upon the 
reader, this entails a weakening of religious monopolies on meaning. The gradual shift from Scripture to the classics as a high-cultural reference point, from Milton's biblical epic poems at midcentury to Dryden's translation of Virgil in the 1690s, is one indicator of this change. The consequences of this non-deterministic attitude towards language and texts can be assessed with particular clarity in nonconformist circles. Struggling for discursive power and for the power of self-definition, these groups - most notably the Dissenters (see Keeble 1987, Achinstein 2003) - learn to accept that a mere counter-discourse, isolated from more widely accepted cultural forms and norms, is not conducive to their aims. Instead, they adopt the (now standard) rhetoric of contingency in order to prevail. In the words of Richard Kroll, these "communities establish their special claims to discursive authority by exploiting possibilities of choice provided by the accepted discourse, though in the process they risk compromising their peculiar and alienated vision" (1991, 78).

Daniel Defoe, for instance, in his anti-deist Essay upon Literature (1726), while arguing for the "Proposition" "that Writing and the use of Letters is of divine Original, and that there was no knowledge of Letters, much more of Writing, before that of the two Tables of Stone written by the Finger of God in Mount Sinai” (1999, 22), does not simply assert this as a matter of faith, but employs the standard discourse of opinion and probabilistic inference: "This so exactly agrees with what I have already advanc'd from Reason, and the Nature of things, that I think it amounts to as much Confirmation of it, as History can yeild [sic] us" (39); "What is said already, fully confirms me in the Opinion" (40); "we find reason to believe" (33); "all Argument from Probability seems to be against them. On the other Hand, there is the highest Probability, that [. . .]” (ibid.), and so on. Although Defoe argues for what he deems to be absolutely certain, he cannot but present his argument in rhetorical terms that are relative, conditional, and limited by the discursive rules of contingency and probability in order to gain authority, legitimacy, and persuasive force with a wider public .

The extent to which the epistemology of neoclassicism is being incorporated even into concepts of authorial self-presentation by radical Protestants in the Restoration period can not only be gauged in Milton's proems to Paradise Lost, which emphasise the speaker's insecurity to the point of exaggeration. Something similar happens in Bunyan's preface to The Pilgrim's Progress (1678), “The Author's Apology For His Book", where Bunyan anticipates negative responses to his book. He reports on what "others" have said about it, thus frankly and openly admitting divergent opinions:

Well, when I had thus put mine ends together, I shew'd them others, that I might see whether They would condemn them, or them justifie: And some said, let them live; some, let them die: Some said, John, print it; others said, Not so: Some said, It might do good; others said, No. 
His solution to this dilemma (the "straight" he is in, 1. 11) is publication:
At last I thought, Since you are thus divided, I print it will, and so the case decided.
For, thought I; Some I see would have it done, Though others in that Channel do not run;
To prove then who advised for the best,
Thus I thought fit to put it to the test.

(ll. 13-18)

The public is given the final word on the quality (and not merely the literary quality) of the work. Bunyan's defence of the book's validity and truthfulness ("advance of Truth", 5, 1. 32) and his objective as a writer to "Make [Truth] cast forth its rayes as light as day" $(6,1.18)$ must be cast in a rhetorical mould of uncertainty, probability, and experiment ("test”, 2, 1. 18). In the "Apology", readers are asked to suspend their judgement until further notice, or until further revelations of truth have occurred: "Forbear to judge, till you do further see. / If that thou wilt not read, let it alone; / Some love the meat, some love to pick the bone" (2, 11. 26-28).

The evolution of early modern literary culture appears as a history of both internal and external contingencies of textual communication. This history is about the emergence of a literary medium of entertainment ('fiction', 'the novel') out of a number of heterogeneous genres, forms, and types of publication; however, these alternative forms of literary communication and their discursive conditions are retrospectively occluded. In this book, I have attempted to outline the complex spectrum of seventeenth-century literary culture without constricting it to a teleological goal 'towards the modern novel'.

The social, economic, and political ramifications of public discourse in seventeenth-century England are complex and manifold, and they forbid simplistic descriptions of a 'from-to' trajectory. Yet, even though scholars have rightly become suspicious of totalising labels, I think the term 'neoclassicism' recommends itself as a description of later seventeenth- and eighteenth-century literature because it is useful in connecting the early efforts of Davenant and Hobbes with the succeeding works of Dryden, Pope, and, to some extent, Johnson in developing a 'modern' literary theory and practice. There is, in other words, a long seventeenth as as well as a long eighteenth century. I have been less interested in neoclassicism as a doctrine or system than as a discourse: as a series of particular moves and engagements in an ongoing argument, a debate about the appropriateness of certain cultural selfrepresentations, and about the modalities of articulating these representations as they evolve over time.

The definition of neoclassicism or neoclassical discourse developed and employed in this study entails a widening of its implications. Neoclassicism is more 
than a literary trend of emphasising the Aristotelian unities and the distinct requirements ('proprieties') of different genres. It could be argued that, for a while, neoclassicism functioned as a highly successful cultural compromise, the implications of which transcend the boundaries of literary criticism by providing moral as well as aesthetic grounds on which to establish a dominant discourse of politeness, sociability, and civility - a discourse that, as we have seen, pervaded even into those areas of English society that could not claim cultural dominance. Furthermore, neoclassical poetics established a canon of precepts or rules that served to ameliorate the insecurity of reader-writer relations that was frequently diagnosed and experienced in early modern print culture. However, it is important to see this not merely as a literary project but as a wider cultural trend (within which literary questions have an important role to play): as a public debate about how contingency (in questions of knowledge, politics, and individual choices and constraints) can be accommodated and articulated.

Along these lines, neoclassicism anchored literary communication in the context of an emerging civic society. It promoted politeness-oriented, depoliticised discursive norms. It provided a solid groundwork that allowed for more flexibility and variation, more disagreement, more democratic and individual liberties, without risking the breakdown of society into civil war. From Dryden's Essay of Dramatick Poesie onwards, one can see how literary politics in the seventeenth century turned away from internecine to more international forms of contest and competition. Within this changing framework, one can observe a whole cluster of functional changes within literary communication (some of them going back to the erosion of late humanist practices of reading and writing):

- an individualisation of readers and readings, presupposing a contingent and irreducible individuality-as-difference that cannot be contained socially and yet is elevated to the position of a social and discursive norm;

- a non-deterministic attitude to language and meaning, including a loss of authority of religious monopolies on interpretation, accompanied by political restraint and the toleration of divergent opinions;

- probability becomes the epistemic norm, verisimilitude the literary norm. The ideal literary style is described by norms of "true proportion" (Dryden) and “propriety of speech" (Locke);

- the introduction of normative distinctions between genres and text types; reflecting and incorporating these distinctions, the novel emerges as a provisional and hybrid literary form that focuses on social and epistemic contingency.

English neoclassicism achieved a successful reduction of social and political complexity - not least by establishing a 'literary culture' along these lines, by means of and in terms of aesthetics and poetics. Its order of discourse remained stable for a fairly long time, at least until the Romantic period, as an "isomorphism of knowledge, literary structure, and implied procedures of interpretation” (Patey 1984, 174). 
By the late seventeenth century, knowledge had become a process of continuous revision of prejudices and hypotheses. It had become provisional, falsifiable, subject to the contingency of the individual's limited powers of observation and to experimental empirical testing of its intersubjective validity. More importantly in the context of this study, this development was not confined to science but occurred in English culture as well, and in English literature in particular. Early modern poets, dramatists, and novelists developed new perspectives on the ways in which worlds and selves are being made. As they envisaged contingency from numerous different angles, works of literature had a substantial share in the rise of neoclassical discourse, and thus in the creation of the modern world. 
